\title{
Determination of carbon-bonded sulfur in soils by hydriodic acid reduction and hydrogen peroxide oxidation
}

\author{
Shan Xiao-quan, Chen Bin \\ Research Centre for Eco-Environmental Sciences, Academia Sinica, P.O. Box 2871, Beijing 100085, People's Republic of China
}

Received: 21 June 1994/Revised: 7 November 1994/Accepted: 10 November 1994

\begin{abstract}
A sequential extraction method has been developed for the determination of carbon-bonded sulfur in soils. The soil sample has been sequentially reduced with $\mathrm{HI}$ and oxidized with hydrogen peroxide, and finally the residue has been digested with a mixture of nitric acid and perchloric acid. All inorganic sulfur components and ester sulfur has been reduced to $\mathrm{H}_{2} \mathrm{~S}$ by $\mathrm{HI}$ except the unreducible sulfur including pyritic sulfur, carbon-bonded sulfur and a previously unidentified sulfur fraction. Whereas a part of the carbon-bonded sulfur has been dissolved in the HI reducing solution another part of carbon-bonded sulfur was removed by hydrogen peroxide oxidation. The total carbon-bonded sulfur compose for oxic soils of the $\mathrm{HI}$-dissolved sulfur and the $\mathrm{H}_{2} \mathrm{O}_{2}$-oxidized sulfur. However, because the pyritic sulfur can be completely decomposed by $\mathrm{H}_{2} \mathrm{O}_{2}$, this form of sulfur should be subtracted from the sum of the two sulfur fractions in case of anoxic soils. Unidentified sulfur components were also detected in the residue after the sequential extraction.
\end{abstract}

\section{Introduction}

Sulfur occurs in soils mainly in organic forms, which can be divided into two distinct fractions: ester sulfur (organic sulfates containing C-O-S linkages, e.g. choline sulfate, phenolic sulfates, sulfated polysaccharides) and carbonbonded sulfur, in which sulfur is directly bonded to carbon, consisting mainly of sulfur containing amino acids, such as methionine and cysteine.

To determine carbon-bonded sulfur in soils, Frenzy et al. [1] investigated Raney nickel, which reduced hydrocarbon-bonded sulfur to inorganic sulfide, but as the sulfur in many inorganic compounds and sulfur in organic compounds, such as cysteine-S-sulfonate is not directly bonded to carbon, the Raney nickel method was not specific for sulfur bonded to carbon. Recently, a Sn$\mathrm{H}_{3} \mathrm{PO}_{4}$ method was reported for the reduction of organic sulfur in soils [2], this method was not specific for carbonbonded sulfur either and would attack a variety of organic and inorganic sulfur compounds.

Correspondence to: Shan Xiao-quan
Since no specific and direct methods are available, carbon-bonded sulfur is estimated in soil and sediment samples as difference between total sulfur and all the other sulfur fractions. Nriagu and Soon [3] subdivided the sulfur fractions in unpolluted and highly polluted sediments into acid volatile sulfur, $\mathrm{HCl}$-soluble sulfur, elemental sulfur, pyrite sulfur, ester sulfur and carbonbonded sulfur as difference between total sulfur and all of the other fractions. David et al. [4] classified the sulfur into total sulfur, hydriodic acid-reducible sulfur (HI-S) and $\mathrm{Zn}-\mathrm{HCl}$ reducible sulfur $(\mathrm{Zn}-\mathrm{HCl}-\mathrm{S})$. $\mathrm{HI}-\mathrm{S}$ includes all inorganic sulfur and non-carbon-bonded sulfur, while $\mathrm{Zn}$-HCl-S includes most of the non-sulfate sulfur, i.e. sulfides, sulfites, elemental sulfur and thiosulfates. Here the carbon-bonded sulfur was determined as the difference between total sulfur and HI-S. Shan et al. [5] divided sulfur in soils into water soluble sulfur, adsorbed sulfur, $\mathrm{HCl}$-volatile sulfur, dilute $\mathrm{HCl}$ soluble sulfur, pyritic sulfur, ester sulfur and carbon-bonded sulfur as difference between the total sulfur and all the other sulfur fractions. In general, quite similar methods were used by numerous researchers [6-12]. The main drawback of these methods is the error, which is the sum of all errors of each fraction and can therefore be large especially for small values of carbon-bonded sulfur.

Another approach to determine the carbon-bonded sulfur in soils is based on the linkage of sulfur to carbon and the quantitative removal or destruction of organic matter in soils.

For this purpose hydrogen peroxide is often used under different experimental conditions [13]. Obviously Sequi and Aringhiori [14] found that the presence of $0.1 \mathrm{~mol} \cdot 1^{-1} \mathrm{Na}_{4} \mathrm{P}_{2} \mathrm{O}_{7}$ at $\mathrm{pH} 7$ substantially improved the effectiveness of $\mathrm{H}_{2} \mathrm{O}_{2}$ in removing organic matter from soil due to the chelating action of pyrophosphate, but the procedure was tedious and time-consuming. In some of the sequential extractions, $\mathrm{H}_{2} \mathrm{O}_{2}$ in an acidic solution was adopted to oxidize organic matter in soil and sediment [15-17] at a higher temperature $\left(85 \pm 2{ }^{\circ} \mathrm{C}\right)$. But the oxidation of organic matter was incomplete, about $10-20 \%$ organic carbon remained in the residue.

Therefore a method for the determination of carbonbonded sulfur in soils is developed. A previously unidentified sulfur fraction is found, thus a more accurate determination of carbon-bonded sulfur is warranted. 


\section{Experimental section}

\section{Apparatus}

A Jarrell-Ash model $1155 \mathrm{~V}$ AtomComp polychromator (Jarrell-Ash Division, Fisher Scientific Company. Waltham MA, USA) was used for the determination of sulfur at SI $180.74 \mathrm{~nm}$. The spectral interferences were corrected [5]. The detection limit ( $2 \sigma$ of 10 replicate measurements) was found to be $11 \mu \mathrm{g} \mathrm{L}^{-1}$.

The distillation/reflux apparatus described by Landers et al. [6] was modified. The details of the apparatus were described previously [5].

\section{Reagents}

The HI reducing solution was prepared according to Landers et al. [6]. All other chemical used in this study were of analytical reagent grade.

\section{Soils}

The four surface soils $(0-15 \mathrm{~cm})$ used were collected from different provinces of China. The zones encompass an environmental gradient ranging from frigid through temperate to subtropics resulting in soils that vary in nature and amounts of the soil organic matter present as well as in other chemical and physical properties. Table 1 shows some of the soil characteristics.

The soils were air-dried at room temperature, ground to pass a $2 \mathrm{~mm}$ sieve, and stored at room temperature. Before analysis and fractionation the soils were subsampled, larger undecomposed plant material removed, and finely ground to $<100$ mesh.

\section{Organic carbon measurement}

Organic carbon was determined by a routine analysis method [18].

\section{Sulfur fractionation}

Total sulfur. An accurately weighed soil sample $(0.50 \mathrm{~g})$ was placed into a $50 \mathrm{~mL}$ conical flask, and a minimum volume of $0.1 \mathrm{~mol} \cdot 1^{-1} \mathrm{HNO}_{3}$ was added to moisten the sample thoroughly, then $10 \mathrm{~mL}$ of conc. $\mathrm{HNO}_{3}(67 \%)$ and $2 \mathrm{~mL}$ of conc. $\mathrm{HClO}_{4}(70 \%)$ were added. The flask was

Table 1. Some characteristics of soil samples

\begin{tabular}{lllllr}
\hline Soil & Order & Family & \multicolumn{3}{l}{ Texture $(\%)$} \\
\cline { 3 - 6 } & & & Clay & Silt & Sand \\
\hline Mudanjiang & Mollisol & Sandy-sitty, mixed & 17.8 & 57.1 & 25.1 \\
Changchun & Mollisol & Sandy-silty, mixed & 10.6 & 49.8 & 39.6 \\
Linyi & Entisol & Silty-clayed, mixed & 33.5 & 59.2 & 7.3 \\
Hangzhou & Ultisol & Fine-silty, mixed & 23.4 & 65.0 & 11.6 \\
\hline
\end{tabular}

covered with a small funnel in order to avoid rapid loss of the acids during the digestion. The sample was refluxed on a hot plate until white silica appeared. Then, the small cover was removed, and the content was heated at about $220 \mathrm{C}$ until the volume was reduced to about $0.5 \mathrm{~mL}$. The flask was cooled down to the room temperature and the interior surface of the flask was rinsed with $10 \mathrm{~mL}$ of $0.1 \mathrm{~mol} \cdot 1^{-1} \mathrm{HNO}_{3}$. The solution was heated for a few minutes and filtered with a filter paper. This procedure was repeated for several times. The filtrates were combined and diluted to $50 \mathrm{~mL}$ with distilled water for the final determination.

\section{Sequential extraction}

According to the present sequential extraction procedure the sulfur in soils was divided into four fractions: HIreducible sulfur (previously defined as all inorganic sulfur except for pyritic sulfur and ester sulfur in the literature), HI-dissolved sulfur (carbon-bonded sulfur), $\mathrm{H}_{2} \mathrm{O}_{2}$-oxidized sulfur (carbon-bonded sulfur) and the sulfur in the residue (previously unidentified sulfur fraction in the literature).

HI-reducible sulfur. An accurately weighed soil sample $(1.00 \mathrm{~g})$ was transferred to the boiling flask and connected to the J-N apparatus. The HI-reducing solution $(20 \mathrm{~mL})$ was added dropwise from the dropping funnel.The suspension was refluxed by gently boiling for $1 \mathrm{~h}$ under $\mathrm{N}_{2}$. The $\mathrm{H}_{2} \mathrm{~S}$ gas was trapped in $10 \mathrm{~mL}$ of $0.05 \mathrm{~mol} \cdot 1^{-1}$ $\mathrm{NaOH}$ by a stream of $\mathrm{N}_{2}$ and the sulfide was oxidized with $\mathrm{H}_{2} \mathrm{O}_{2}$ to sulfate. The solution was shaken for a few seconds and allowed to stand for $10 \mathrm{~min}$ to complete the oxidation.

HI-dissolved sulfur. The digest in the boiling flask was filtered with a filter paper into a $50 \mathrm{~mL}$ of volumetric flask. All solid residue was washed thoroughly with distilled water, the washings were combined with the filtrate and the solution diluted to the mark with distilled water. $\mathrm{H}_{2} \mathrm{O}_{2}$-oxidized sulfur. The solid residue on the filter paper was transferred into a $200 \mathrm{~mL}$ conical flask and $20 \mathrm{~mL}$ of $\mathrm{H}_{2} \mathrm{O}_{2}(30 \%)$ was added. The flask was covered with a little funnel and heated gently on a hot plate, the reaction was vigorous and the temperature of the suspension rose to $100-103^{\circ} \mathrm{C}$ within $10 \mathrm{~min}$. After heating for $1 \mathrm{~h}$, the funnel was removed and the solution was evaporated near dryness. Then, another $20 \mathrm{~mL}$ of $\mathrm{H}_{2} \mathrm{O}_{2}(30 \%)$ was added and the digestion was repeated. The residue was rinsed with $10 \mathrm{~mL}$ of $0.10 \mathrm{~mol} \cdot 1^{-1} \mathrm{HNO}_{3}$, the digest was filtered into a $50 \mathrm{~mL}$ volumetric flask, the procedure was repeated for several times. Finally, the solution was diluted to the mark with $0.1 \mathrm{~mol} \cdot 1^{-1} \mathrm{HNO}_{3}$.

Residue sulfur. The solid residue on the filter paper was transferred into a $100-\mathrm{mL}$ conical flask, and a quite similar procedure was performed using $20 \mathrm{~mL}$ of $\mathrm{HNO}_{3}$ and $4 \mathrm{~mL}$ of $\mathrm{HClO}_{4}$.

Pyritic sulfur.A subsample of the soil $(0.5 \mathrm{~g})$ was treated as for HI-reducible sulfur and HI-dissolved sulfur. To the solid residue on the filter paper transferred back to the boiling flask, $3.0 \mathrm{~g}$ of granular zinc was added. The flask was attached to the J-N apparatus and purged with $\mathrm{N}_{2}$ at 2 bubbles/s. $\mathrm{HCl}\left(20 \mathrm{~mL}, 6 \mathrm{~mol} \cdot 1^{-1}\right)$ was added in three 
portions from the dropping funnel. After the initial vigorous reaction the flask was boiled gently for $1 \mathrm{~h}$. The $\mathrm{H}_{2} \mathrm{~S}$ gas was trapped in $10 \mathrm{~mL}$ of $0.05 \mathrm{~mol} \cdot 1^{-1} \mathrm{NaOH}$ and then oxidized to sulfate with $\mathrm{H}_{2} \mathrm{O}_{2}$ as described above.

\section{Optimization of $\mathrm{H}_{2} \mathrm{O}_{2}$ oxidation procedures}

To optimize the digestion of soil organic matter, several $\mathrm{H}_{2} \mathrm{O}_{2}$ oxidation methods reported in the literature were tested (Table 2).

\section{Results and discussion}

Effectiveness of $\mathrm{H}_{2} \mathrm{O}_{2}$ in destroying organic matter in soil

Because sulfur is directly bonded to carbon in the carbonbonded sulfur compounds, the main assumption for the final determination of sulfur is to selectively reduce the carbon-bonded sulfur to $\mathrm{H}_{2} \mathrm{~S}$ gas or to quantitatively destroy or remove organic matter from the soils. As no specific reduction reaction seems to be available to meet the former requirement emphasis is put on the latter. For this purpose a comparison was carried out between various pretreatment procedures for soils (Table 2) and their effectiveness in releasing organic carbon (Table 3)

The organic carbon content in untreated soils are in the range of $0.80-3.74 \%$. When soil samples were treated by $\mathrm{HI}$ reducing solution, part of the organic carbon was removed. If diluted $\mathrm{H}_{2} \mathrm{O}_{2}$ solutions $\left(\mathrm{H}_{2} \mathrm{O}_{2}\right.$ - $\mathrm{I}$ and $\mathrm{H}_{2} \mathrm{O}_{2}$ -
II) or a mixture of $\mathrm{HNO}_{3}-\mathrm{H}_{2} \mathrm{O}_{2}$ were used more but not all organic carbon was recovered. Almost all the organic carbon was transferred to the solution by $\mathrm{H}_{2} \mathrm{O}_{2}$ $\mathrm{Na}_{4} \mathrm{P}_{2} \mathrm{O}_{7}$, and the organic carbon remaining in the residue was only in the range of $1.9-4.5 \%$, but this method is time-consuming and the strong color of the extract may cause troubles in the final ICP-AES determination. Using the method developed here a more efficient oxidation was achieved, with small organic carbon remaining in the residue which was close to the detection limit of the routine method of organic carbon determination. In addition, the procedure is time-saving and the extract solution exhibits only a very slight color and is therefore more suitable for ICP-AES determinations.

To examine whether carbon-bonded sulfur compounds could be destroyed and/or oxidized to sulfate by $\mathrm{H}_{2} \mathrm{O}_{2}$ oxidation, several typical carbon-bonded sulfur compounds such as methionine, cystine, taurine and thiamine were added to soil samples. Then, the total sulfur concentrations were determined by ICP-AES and ion chromatography (IC) [3], and the recovery of carbon-bonded sulfur was determined (Table 4). Quantitative recoveries of carbon-bonded sulfur compounds were obtained and a very good agreement was achieved between recoveries determined by ICP-AES and by IC leading to the conclusion that all the carbon-bonded sulfur compounds were destroyed and oxidized to sulfate by $\mathrm{H}_{2} \mathrm{O}_{2}$-oxidation.

As there are numerous reports on the performance of HI-reduction in the literature [5] and it is well recognized that all inorganic sulfur compounds except for pyritic sulfur and ester sulfur can be reduced to $\mathrm{H}_{2} \mathrm{~S}$ by $\mathrm{HI}$

Table 2. Comparison of digestion methods from literature

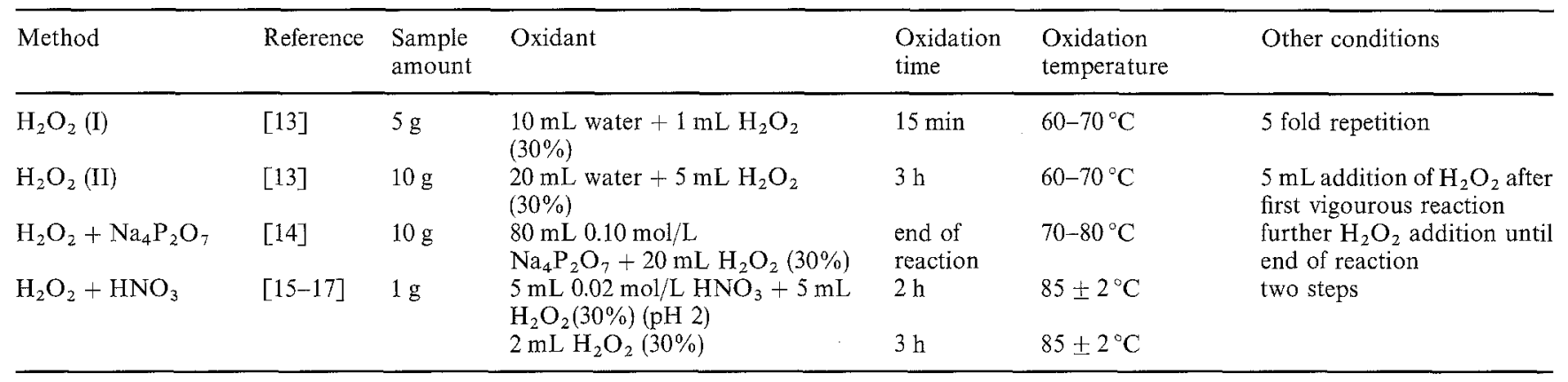

Table 3. Organic carbon in soils and in residues after various treatment ${ }^{2}$ (conditions see Table 2)

\begin{tabular}{llllllll}
\hline Soil & \multicolumn{6}{l}{ Organic carbon (\%) } \\
\cline { 2 - 7 } & $\begin{array}{l}\text { Untreated } \\
\text { soil }\end{array}$ & $\begin{array}{l}\mathrm{HI} \\
\text { reduction }\end{array}$ & $\mathrm{H}_{2} \mathrm{O}_{2}-\mathrm{I}$ & $\mathrm{H}_{2} \mathrm{O}_{2}-\mathrm{II}$ & $\begin{array}{l}\mathrm{H}_{2} \mathrm{O}_{2}+ \\
\mathrm{HNO}_{3}\end{array}$ & $\begin{array}{l}\mathrm{H}_{2} \mathrm{O}_{2}+ \\
\mathrm{Na}_{4} \mathrm{P}_{2} \mathrm{O}_{7}\end{array}$ & $\begin{array}{l}\text { Present } \\
\text { method }\end{array}$ \\
\hline Mudanjiang & 3.58 & 1.86 & 0.91 & 0.55 & 0.22 & 0.06 & 0.028 \\
& 3.62 & 1.88 & 0.89 & 0.55 & 0.21 & 0.08 & 0.024 \\
Changchun & 1.74 & 1.43 & 0.80 & 0.37 & 0.19 & 0.07 & 0.030 \\
Linyi & 1.70 & 1.46 & 0.76 & 0.35 & 0.21 & 0.09 & 0.027 \\
& 0.80 & 0.57 & 0.31 & 0.20 & 0.13 & 0.03 & 0.010 \\
Hangzhou & 0.80 & 0.55 & 0.29 & 0.21 & 0.11 & 0.03 & 0.013 \\
& 3.71 & 2.71 & 1.58 & 0.93 & 0.35 & 0.12 & 0.023 \\
& 3.77 & 2.61 & 1.54 & 0.90 & 0.35 & 0.11 & 0.025 \\
\hline
\end{tabular}

${ }^{\mathrm{a}} \mathrm{H}_{2} \mathrm{O}_{2}$ treatment was performed on the residue after $\mathrm{HI}$ reduction 
Table 4. Recovery of carbon-bonded sulfur added to soil after $\mathrm{H}_{2} \mathrm{O}_{2}$ oxidation

\begin{tabular}{|c|c|c|c|c|c|c|c|c|c|}
\hline Soil & $\begin{array}{l}\text { Soil } \\
\text { weight } \\
\text { (mg) }\end{array}$ & Compound & $\begin{array}{l}\text { Sulfur } \\
\text { species }\end{array}$ & Soil & Added $^{\mathrm{a}}$ & \multicolumn{2}{|c|}{ Total sulfur } & ICP-AES & IC \\
\hline \multirow[t]{2}{*}{ Mudanjiang } & \multirow[t]{2}{*}{500} & \multirow[t]{2}{*}{ Methionine } & \multirow[t]{2}{*}{$-\mathrm{C}-\mathrm{S}-\mathrm{C}-$} & \multirow[t]{2}{*}{332} & \multirow[t]{2}{*}{200} & 517.2 & 499.0 & 97.2 & 93.8 \\
\hline & & & & & & 513.8 & 505.4 & 96.6 & 95.0 \\
\hline \multirow[t]{2}{*}{ Mudanjiang } & \multirow[t]{2}{*}{500} & \multirow[t]{2}{*}{ Taurine } & \multirow{4}{*}{$-\mathrm{C}-\mathrm{SO}_{2} \mathrm{OH}$} & \multirow[t]{2}{*}{332} & \multirow[t]{2}{*}{200} & 512.6 & 490.2 & 96.3 & 92.1 \\
\hline & & & & & & 506.6 & 491.8 & 95.2 & 92.4 \\
\hline \multirow[t]{2}{*}{ Mudanjiang } & \multirow[t]{2}{*}{500} & \multirow[t]{2}{*}{ Thiamine } & & \multirow[t]{2}{*}{332} & \multirow[t]{2}{*}{200} & 529.3 & 515.7 & 99.5 & 96.9 \\
\hline & & & & & & 524.1 & 508.9 & 98.5 & 95.6 \\
\hline
\end{tabular}

${ }^{\text {a }}$ Added as carbon-bonded sulfur

Table 5. Carbon-bonded sulfur reduced and dissolved by HI reduction solution ( $\%$ of total sulfur)

\begin{tabular}{llllrr}
\hline Compound & $\begin{array}{l}\text { Sulfur added as } \\
\text { carbon-bonded } \\
\text { sulfur }(\mu \mathrm{g})\end{array}$ & \multicolumn{2}{l}{\begin{tabular}{l} 
Sulfur found $(\%)$ \\
\cline { 3 - 6 }
\end{tabular}} & $\begin{array}{l}\text { HI-reducible } \\
\text { sulfur }\end{array}$ & \multicolumn{2}{l}{$\begin{array}{l}\text { In HI reducing } \\
\text { solution }\end{array}$} \\
\hline Methionine & 1000 & 0.42 & 0.46 & 96.0 & 95.2 \\
Cystine & 1000 & 0.25 & 0.23 & 100.9 & 103.1 \\
Taurine & 1000 & 0.11 & 0.11 & 99.8 & 99.3 \\
Thiamine & 1000 & 0.63 & 0.65 & 97.1 & 97.9 \\
\hline
\end{tabular}

reduction, one can infer that the combination of HI-reduction and $\mathrm{H}_{2} \mathrm{O}_{2}$-oxidation probably offers a sequential extraction procedure for the determination of carbonbonded sulfur in soils.

\section{Validity of the sequential extraction procedure for the determination of carbon-bonded sulfur}

To examine the sequential extraction procedure of HIreduction followed by $\mathrm{H}_{2} \mathrm{O}_{2}$ oxidation for the determination of carbon-bonded sulfur in soils, a series of experiments were carried out. Several typical carbon-bonded sulfur compounds such as methionine, cystine, taurine and thiamine were chosen to verify whether $\mathrm{HI}$ is able to reduce these compounds to $\mathrm{H}_{2} \mathrm{~S}$. The results are shown in Table 5. It indicated that the carbon-bonded sulfur compounds were not reduced to $\mathrm{H}_{2} \mathrm{~S}$ by $\mathrm{HI}$ and almost completely remained in the HI reducing solution. Additionally, some of inorganic minerals present in the soil such as montmorillonite, illite, K-feldspar and pyrite containing no organic matter were also investigated. The minerals were subjected to HI-reduction followed by $\mathrm{H}_{2} \mathrm{O}_{2}$-oxidation, and the sulfur remaining in the residue after the above sequential treatments was determined after the digestion with a mixture of $\mathrm{HNO}_{3}-\mathrm{HClO}_{4}$. The organic carbon contents in the samples were also measured. All the results are summarized in Table 6 . Sulfur in the montmorillonite, illite and $\mathrm{K}$-feldspar can be reduced to $\mathrm{H}_{2} \mathrm{~S}$ by $\mathrm{HI}$. No sulfur was detected either in the HIreducing solution nor after $\mathrm{H}_{2} \mathrm{O}_{2}$ oxidation. Although pyritic sulfur cannot be reduced to $\mathrm{H}_{2} \mathrm{~S}$ by HI-reduction, it can be decomposed by $\mathrm{H}_{2} \mathrm{O}_{2}$ oxidation. The reason for $4 \%$ of sulfur in the pyrite being reduced to $\mathrm{H}_{2} \mathrm{~S}$ by $\mathrm{HI}$ was probably due to impurities like other sulfur compounds present.

Residual sulfur fractions were found after the HI reduction $/ \mathrm{H}_{2} \mathrm{O}_{2}$ oxidation, not being identified in the literature.

Humic substances complex and poor-defined polydisperse mixtures of heterogeneous organic polyelectrolytes [19] are the major component of soil organic matter and contain the bulk of the total sulfur in many soils, particularly in humid regions. Purified commercial and soil humic acids were subjected to $\mathrm{HI}$-reduction and $\mathrm{H}_{2} \mathrm{O}_{2}$ oxidation, the sulfur was divided into HI-reducible sulfur, HI-dissolved sulfur and $\mathrm{H}_{2} \mathrm{O}_{2}$-oxidized sulfur fractions (Table 7). Since all humic acids were destroyed by $\mathrm{H}_{2} \mathrm{O}_{2}$ oxidation no residue remained. The HI-reducible sulfur fraction includes ester sulfur and all inorganic sulfur fractions except pyritic sulfur and unidentified residue sulfur. The HI-dissolved sulfur fraction can be related to the carbon-bonded sulfur, $\mathrm{H}_{2} \mathrm{O}_{2}$-oxidized sulfur includes carbon-bonded sulfur and pyritic sulfur. If the humic acids were directly destroyed by $\mathrm{H}_{2} \mathrm{O}_{2}$ without the sequential pretreatment or by the mixture of $\mathrm{HNO}_{3}$ and $\mathrm{HClO}_{4}$ the total sulfur concentrations were quite similar, no matter what method was used. This finding further verified that all organic matter was quantitatively destroyed by $\mathrm{H}_{2} \mathrm{O}_{2}$ oxidation.

Based on the above study a sequential extraction procedure was proposed for the determination of carbonbonded sulfur in soils as given in the experimenal section.

\section{Determination of carbon-bonded sulfur in soils}

The recommended sequential procedure was applied to the determination of carbon-bonded sulfur in soils. The results are given in Table 8 . 
Table 6. Sulfur fractions of several natural minerals

\begin{tabular}{|c|c|c|c|c|c|c|c|c|c|}
\hline \multirow[t]{2}{*}{ Mineral } & \multirow{2}{*}{$\begin{array}{l}\text { Sample } \\
\text { weight } \\
\text { (g) }\end{array}$} & \multicolumn{7}{|c|}{ Sulfur fraction $(\mu \mathrm{g} / \mathrm{g})$} & \multirow{2}{*}{$\begin{array}{l}\text { Organic carbon } \\
\text { content }\end{array}$} \\
\hline & & \multicolumn{2}{|c|}{ HI-reducible S } & \multirow{2}{*}{$\frac{\text { HI-dissolved S }}{\mathrm{ND}^{\mathrm{a}}}$} & \multicolumn{2}{|c|}{$\mathrm{H}_{2} \mathrm{O}_{2}$-removed $\mathrm{S}$} & \multicolumn{2}{|c|}{ Residue S } & \\
\hline Montmorillonite & 2.00 & 216.0 & 211.0 & & \multicolumn{2}{|c|}{ ND } & 163.2 & 167.9 & 0.01 \\
\hline Illite & 2.00 & 143.7 & 145.9 & ND & \multicolumn{2}{|c|}{ ND } & 150.5 & 153.5 & ND \\
\hline K-feldspar & 2.00 & 141.3 & 147.1 & ND & \multicolumn{2}{|c|}{ ND } & 134.3 & 128.5 & ND \\
\hline Pyrite & 0.05 & $22.2^{\mathrm{b}}$ & $22.6^{\mathrm{b}}$ & ND & $532.0^{\mathrm{b}}$ & $527.4^{\mathrm{b}}$ & & & ND \\
\hline
\end{tabular}

${ }^{a} \mathrm{ND}$ - Not detected

${ }^{\mathrm{b}}[\mathrm{mg} / \mathrm{g}]$.

Table 7. Sulfur in humic acid $[\mu \mathrm{g} / \mathrm{g}]$

\begin{tabular}{|c|c|c|c|c|c|c|c|c|c|c|}
\hline \multirow{3}{*}{$\begin{array}{l}\text { Humic acid } \\
\text { Shanhai }\end{array}$} & \multicolumn{6}{|c|}{ Sequential extraction } & \multicolumn{4}{|c|}{ Total sulfur } \\
\hline & \multicolumn{2}{|c|}{ HI-reducible S } & \multicolumn{2}{|c|}{ HI-dissolved S } & \multicolumn{2}{|c|}{$\mathrm{H}_{2} \mathrm{O}_{2}$-oxidized $\mathrm{S}$} & \multicolumn{2}{|c|}{$\begin{array}{l}\text { After } \mathrm{H}_{2} \mathrm{O}_{2} \\
\text { oxidation }\end{array}$} & \multicolumn{2}{|c|}{$\begin{array}{l}\text { After digestion } \\
\text { with } \\
\mathrm{HNO}_{3} / \mathrm{HClO}_{4}\end{array}$} \\
\hline & 269 & 263 & 585 & 571 & 670 & 696 & 1528 & 1552 & 1568 & 1592 \\
\hline Beijing-1 & 578 & 562 & 2162 & 2196 & 2080 & 2060 & 4845 & 4821 & 4982 & 4948 \\
\hline Beijing-2 & 1335 & 1367 & 1759 & 1765 & 2372 & 2342 & 5551 & 5589 & 5621 & 5645 \\
\hline
\end{tabular}

Table 8. Carbon-bonded sulfur in soils $[\mu \mathrm{g} / \mathrm{g}]$

\begin{tabular}{|c|c|c|c|c|c|c|c|c|c|c|c|c|}
\hline \multirow[t]{2}{*}{ Soil } & \multicolumn{8}{|c|}{ Sulfur fraction } & \multicolumn{2}{|c|}{ Carbon-bonded sulfur } & \multicolumn{2}{|c|}{ Total sulfur } \\
\hline & \multicolumn{2}{|c|}{ HI-reducible $\mathrm{S}$} & \multicolumn{2}{|c|}{ HI-dissolved S } & \multicolumn{2}{|c|}{$\mathrm{H}_{2} \mathrm{O}_{2}$-removed S } & \multicolumn{2}{|c|}{ Residue S } & \multicolumn{2}{|c|}{$\begin{array}{l}\mathrm{HI} \text {-dissolved }+\underset{\mathrm{S}}{\mathrm{H}_{2} \mathrm{O}_{2} \text {-removed }} \mathrm{S}\end{array}$} & & \\
\hline Mudanjiang & 272.5 & 260.3 & 194.0 & 190.0 & 130.0 & 138.0 & 89.0 & 83.0 & 324.0 & 328.0 & 672.0 & 656.0 \\
\hline Changchun & 566.0 & 559.8 & 291.5 & 302.5 & 155.5 & 148.9 & 147.0 & 139.0 & 447.0 & 451.4 & 1220.0 & 1186.0 \\
\hline Linyi & 120.4 & 131.2 & 52.2 & 56.8 & 75.0 & 69.0 & 44.5 & 38.1 & 127.2 & 125.8 & 302.2 & 317.6 \\
\hline Hangzhou & 553.5 & 566.2 & 380.0 & 369.0 & 258.0 & 264.0 & 101.2 & 105.0 & 638.0 & 633.0 & 1290.0 & 1306.0 \\
\hline
\end{tabular}

Since all these soils are oxic agricultural soils in which no pyritic sulfur was detectable, carbon-bonded sulfur was determined by summing HI-dissolved sulfur and $\mathrm{H}_{2} \mathrm{O}_{2}$-oxidized sulfur. Organic carbon content in these soils and in the soil residues after sequential extraction were determined (Table 3). As can be seen from Table 8 , total sulfur in these soils differed drastically (from the minimum value of $309.9 \mu \mathrm{g} / \mathrm{g}$ in Linyi soil to the maximum value of $1298 \mu \mathrm{g} / \mathrm{g}$ in Hangzhou soil). But these total sulfur values were in significant correlation with the organic carbon values $(r=0.729)$, indicating most of the total sulfur are organicbound. HI-reducible sulfur accounted for about $40 \%$ of the total sulfur $(40.1-46.8 \%)$, ester sulfur would be smaller. HI-dissolved carbon-bonded sulfur values were higher than that obtained by $\mathrm{H}_{2} \mathrm{O}_{2}$ oxidation except Linyi soil. But only a small portion of organic carbon was removed by HI (see Table 3), suggesting the organic matter containing sulfur was dissolved by HI. This was likely to be fulvic acid which is dissolved in acid medium.

In the case of anoxic soils there are various amounts of pyritic sulfur present, which can be recovered by $\mathrm{H}_{2} \mathrm{O}_{2^{-}}$ oxidation treatment. Therefore, a subtraction of the py- ritic sulfur is required from the sum of HI-dissolved sulfur and $\mathrm{H}_{2} \mathrm{O}_{2}$-oxidized sulfur fractions.

\section{Residue sulfur fractions}

Traditionally, many researchers believe that all inorganic sulfur fractions and ester sulfur can be reduced to $\mathrm{H}_{2} \mathrm{~S}$ by HI-reduction except for pyritic sulfur and carbon-bonded sulfur fractions. Therefore, subtraction method is frequently used for the estimation of carbon-bonded sulfur after the determination of the above mentioned sulfur fractions. However, residual sulfur fractions were detected in the present study after the sequential treatment and the fractions have not been identified previously in the literature. Although the chemical nature of these fractions are not certain at present, these unidentified sulfur fractions are more likely to be inorganic sulfur because the natural minerals of montmorillonite, illite and $\mathrm{K}$-feldspar contain no organic matter and quite significant contents of residue sulfur have been detected after the sequential treatment. The explanation for the chemical nature of the unidentified sulfur fractions may be quite complicated. David et al. [4] suggested that an unknown proportion of 
inorganic sulfate maybe exist in an occluded form. The discovery of the residue sulfur gave direct evidence for this postulation. Usually, trace metals in soils and sediments have been divided into various fractions by sequential extractions, such as exchangeable, bound to carbonates, bound to Fe-Mn oxides, bound to organic matter and residue. The residual form were thought to be metals being occluded within the crystal structure of the residual solid containing mainly primary and secondary minerals after other fractions have been removed. This may be the same case for residue sulfur.

\section{Conclusion}

Based on the present study the following conclusions can be drawn:

(1) All organic matters in soils can be destroyed and typical carbon-bonded sulfur compounds can be oxidized to sulfate by undiluted $\mathrm{H}_{2} \mathrm{O}_{2}$-oxidation at higher temperatures than that used by other researchers. Pyritic sulfur is also recovered by the $\mathrm{H}_{2} \mathrm{O}_{2}$ treatment. Certain parts of carbon-bonded sulfur are dissolved in HI-reducing solution. Thus, a sequential procedure has been suggested for the determination of carbon-bonded sulfur in soils by $\mathrm{HI}$-reduction followed by $\mathrm{H}_{2} \mathrm{O}_{2}$-oxidation. In the case of oxic soil the carbon-bonded sulfur is the sum of HIdissolved sulfur and $\mathrm{H}_{2} \mathrm{O}_{2}$-oxidized sulfur. For anoxic soil the pyritic sulfur fraction should be subtracted from the above sum.

(2) A previously unidentified sulfur fraction, which is experimentally defined as residue sulfur, is found in soil samples subjected to the above sequential treatment. The residue sulfur is great in comparison to the total sulfur in the soil samples. Therefore, a large error would be introduced in the estimation of carbon-bonded sulfur by the different methods widely used in the literature. This mistake can be avoided by the method recommended.

(3) Further study is still required to develop a better analytical technique for the determination of carbonbonded sulfur. The chemical nature of the residual sulfur needs to be ascertained. Although these questions have not been satisfactorily answered, a certain progress has been made in the determination of carbon-bonded sulfur. The sequential procedure recommended has advantages over methods reported in the literature. The most important aspects of the developed sequential procedure are more accurate determination of carbon-bonded sulfur and discovery of the unidentified sulfur fractions. This will stimulate the research on the chemical characteristics of sulfur.

Acknowledgement. This study was supported by the National Natural Science Foundation of China.

\section{References}

1. Freney JR, Melville GE, Williams CH (1970) Soil Sci $109: 310$

2. Pirela HJ, Tabatabai MA (1988) Soil Sci Soc AM J 52:959

3. Nriagu JO, Soon YK (1985) Geochim Cosmochim Acta $49: 823$

4. David MB, Schindler SC, Mitchell MJ, Strick JE (1983) Soil Biol Biochem 15:671

5. Shan XQ, Chen B, Jin LZ, Zhen Y, Hou XP, Mou SF (1992) Chem Spec Bioaval 4:97

6. Landerst DH, David MB, Mitchell MJ (1983) Intern J Environ Anal Chem 14:245

7. David MB, Mitchell MJ, Nakas JP (1982) Soil Sci Soc Am J $46: 847$

8. Mitchell MJ, Landerst DH, Brodowski DF, Lawrence GB, David MB (1984) Water, Air, Soil Pollution $21: 231$

9. Lowe LE (1986) Can J Soil Sci 66:337

10. Krairapanond N, Delaune RD, Patrick JWH (1991) Soil Sci $151: 261$

11. Houle D, Carignan R (1992) Biogeochem 16:63

12. Stanko-Golden KM, Fitzgerald JW, Swank WT (1992) Soil Biol Biochem 7:693

13. Lavkulich LM, Wiens JH (1970) Soil Sci Soc Amer Proc $34: 755$

14. Sequi P, Aringhieri R (1977) Soil Sci Soc Am J 44:340

15. Tessier A, Campbell PGC, Bisson M (1979) Anal Chem $51: 844$

16. Gupta SK, Chen KY (1975) Environ Lett 10:129

17. Kersten M, Forstner U (1987) Marine Chem 22:299

18. Lao JS (1988) Handbook for soil agricultural and chemical analysis. Agriculture Press, Beijing, p 236

19. de Wit JCM, van Rlemsdijk WH, Koopal LK (1993) Environ Sci Technol 27 (10): 2005 